\title{
Biomodelos Ósseos Produzidos por Intermédio da Impressão 3D: Uma Alternativa Metodológica no Ensino da Anatomia Veterinária
}

\author{
Daniela de Alcântara Leite dos Reis ${ }^{1}$, Beatriz Laura Rojas Gouveia², \\ Brenda Mendonça de Alcântara², Brunna Pereira Saragiotto², Érica Esther Domanski \\ Baumel $^{2}$, Janaina Santos Ferreira ${ }^{2}$, José Carlos Rosa Júnior ${ }^{2}$, Francileusa Delys de Oliveira ${ }^{1}$, \\ Paulo Ramos da Silva Santos ${ }^{1}$ e Antônio Chaves de Assis Neto ${ }^{1,2^{*}}$
}

1Programa de Pós-graduação em Anatomia dos Animais Domésticos e Silvestres da Faculdade de Medicina Veterinária e Zootecnia da Universidade de São Paulo

${ }^{2}$ Faculdade de Medicina Veterinária e Zootecnia da Universidade de São Paulo

* Autor para correspondência: antonioassis@usp.br

\section{RESUMO}

Recursos tecnológicos podem contribuir para o ensino da Anatomia Veterinária, tornando as disciplinas relativas a tal área, que são essenciais para a formação dos estudantes de Medicina Veterinária, cada vez mais atualizadas frente às novas tecnologias e às novas gerações de estudantes. Neste trabalho, o objetivo foi aplicar a digitalização e a impressão 3D para produzir biomodelos dos esqueletos canino e equino, de modo a disponibilizar as peças produzidas como ferramenta alternativa de estudo nas aulas práticas de anatomia veterinária. Ossos de cão e equino foram digitalizados, sendo possível realizar a sua impressão 3D com preservação eficaz das principais estruturas anatômicas. Por meio desse processo, também foi possível gerar arquivos digitais para que sejam utilizados durante as aulas práticas. Além disso, os biomodelos e os arquivos digitais produzidos poderão ser aplicados como uma forma alternativa e complementar para o estudo anatômico do esqueleto canino e equino.

Palavras-Chave: Biomodelagem anatômica; Ossos do Esqueleto; Anatomia Animal.

\begin{abstract}
Technological resources can contribute to the teaching of Veterinary Anatomy, making this discipline, which is basic and essential for students of Veterinary Medicine, more interesting and accurate. In this study, the objective was to apply the 3D scanning and printing to produce biomodels of the canine and equine skeleton proposing to make available the models produced as a study tool in the practical classes of veterinary anatomy. Dog and equine bones were scanned. Then, it was possible to make the 3D printing of these bones with effective preservation of the main anatomical structures. Through scanning, it was also possible to generate digital files aiming their use in the classroom. These biomodels can be applied in the anatomical canine and equine skeleton study.
\end{abstract}

Keywords: Anatomical Biomodeling; Bones; Animal Anatomy.

\section{Introdução}

Com o avanço tecnológico, algumas inovações tornam-se possíveis de serem aplicadas nas salas de aula, favorecendo o processo de ensino-aprendizagem, pois a tecnologia já se encontra bastante presente no cotidiano do estudante. Áreas de pesquisa e educação são grandes beneficiárias dos recursos tecnológicos, podendo contar, por exemplo, com a criação de modelos didáticos e realísticos que simulem o funcionamento dos sistemas corpóreos. Nas áreas da saúde, a impressão 3D ou prototipagem rápida vem sendo empregada na medicina humana, veterinária e odontologia, com a produção dos biomodelos (SEARS et al., 2016, pp. 298-310).

A biomodelagem é um termo que denomina a reprodução das características morfológicas de 
uma estrutura anatômica em um modelo físico, e o biomodelo é o produto desse processo de reprodução física, que pode ser dividido em duas etapas principais: biomodelagem virtual e biomodelagem física ou prototipagem (SILVA, 2014, pp. 125143). A biomodelagem virtual é a etapa responsável pela criação e manipulação de um modelo digital, aprimorando a imagem obtida através de softwares específicos, já a biomodelagem física, ou prototipagem, é a etapa responsável pela obtenção de um modelo físico, através do uso de uma impressora 3D (GRANDE NETO, 2016, pp. 1-56).

$\mathrm{Na}$ área médica, a biomodelagem já é bastante empregada no diagnóstico e planejamento cirúrgico, e dentre os benefícios encontrados na literatura referente ao seu uso estão: a redução do tempo de realização dos procedimentos operatórios, a redução do período de anestesia, do risco de infecção e do número de cirurgias necessárias para a obtenção do resultado final, além da diminuição do custo total do tratamento (HESPEL, WILHITE \& HUDSON, 2014, pp. 1-12).

Porém, em alguns países, os biomodelos também vêm sendo utilizados como instrumentos para o auxílio didático. Anomalias raras podem ser confeccionadas através de biomodelos, e futuramente estes podem ser utilizados como um acervo físico de casos (GRANDE NETO, 2016, pp. 1-56).

$\mathrm{O}$ curso de veterinária de uma universidade na Escócia usou a técnica de biomodelagem 3D para ajudar os alunos a desenvolverem as suas habilidades clínicas como, por exemplo, sutura, punção venosa e anestesia, e alcançar competência nessas habilidades exige profundo conhecimento de estruturas anatômicas. Tem-se argumentado que a capacidade espacial dos alunos pode ajudar esse entendimento anatômico, e que tal capacidade pode ser desenvolvida usando modelos 3D (BOYD, CLARKSON \& MATHER, 2015, pp. 1-2). Os modelos de árvore brônquica de um gato e de um cão saudáveis também foram impressos em 3D para o uso no estudo de endoscopia das vias aéreas superiores, ilustrando assim pontos de referência importantes e servindo como uma ferramenta de ensino para os alunos observarem os procedimentos (HESPEL, WILHITE \& HUDSON, 2014, pp. 1-12).

A aplicação de biomodelos produzidos pela impressão 3D em aulas práticas das disciplinas de anatomia veterinária no Brasil é uma ferramenta inédita. No presente trabalho foram utilizados processos de digitalização para a produção de biomodelos de ossos da espécie canina e equina, a fim de servirem como exemplares para estudos anatômicos.

\section{Materiais e Métodos}

Serviram como modelos os ossos de um cão e de um equino provenientes do Hospital Veterinário da Faculdade de Medicina Veterinária e Zootecnia da Universidade de São Paulo (Hovet-USP). Os cadáveres foram preparados segundo procedimentos estabelecidos de osteotécnica no Laboratório de Anatomia Veterinária da FMVZ-USP.

Os ossos foram digitalizados separadamente, utilizando o aparelho 3D Go!SCAN (Creaform). Esse scanner possui duas câmeras digitais HD, cada uma cercada por um conjunto de quatro lâmpadas LED brancas, e um projetor, que emite um padrão de luz branca. As câmeras detectam a superfície do objeto e fazem a aquisição das imagens, que são exibidas no software VX elements sob a forma de uma malha composta por milhares ou até mesmo milhões de triângulos. Esse software é responsável pela aquisição e processamento de dados 3D resultantes da digitalização feita pelo scanner 3D. As imagens dos ossos se formam em tempo real e o resultado final é um arquivo com extensão ".csf" criado automaticamente. A edição das imagens digitalizadas foi realizada no software Geomagic. Esse software permite a correção das imagens formadas, utilizando ferramentas que possibilitam excluir algumas superfícies que ficaram irregulares, aplanar possíveis saliências formadas, suavizar malhas, reduzir ruídos e preencher falhas (Figura 1).

Em seguida, os ossos foram impressos numa impressora 3D (Mojo 3D Printer). A impressora utiliza tecnologia FDM (Fused Deposition Modeling TM), que emprega um material termoplástico em 
forma de filamento, depositando o material em uma base semiaderente removível. O modelo da impressora 3D usada apresenta uma placa de base para impressão com dimensões $12,7 \mathrm{~cm}$ x $12,7 \mathrm{~cm}$, portanto peças com grandes dimensões foram impressas em mais de uma etapa.

O tempo de impressão de cada peça varia de seis a oito horas e depende do tamanho da peça.
As peças impressas foram submetidas a um processo de limpeza em uma lavadora WaveWash 55 - Stratasys, a fim de remover a resina de suporte, obtendo dessa forma apenas a peça produzida. Nesse processo de limpeza, que dura aproximadamente doze horas, a lavadora necessita de um agente detergente de limpeza especial que remove apenas a resina de suporte (Ecoworks Tablets Cleaning Agent) (Figura 2).
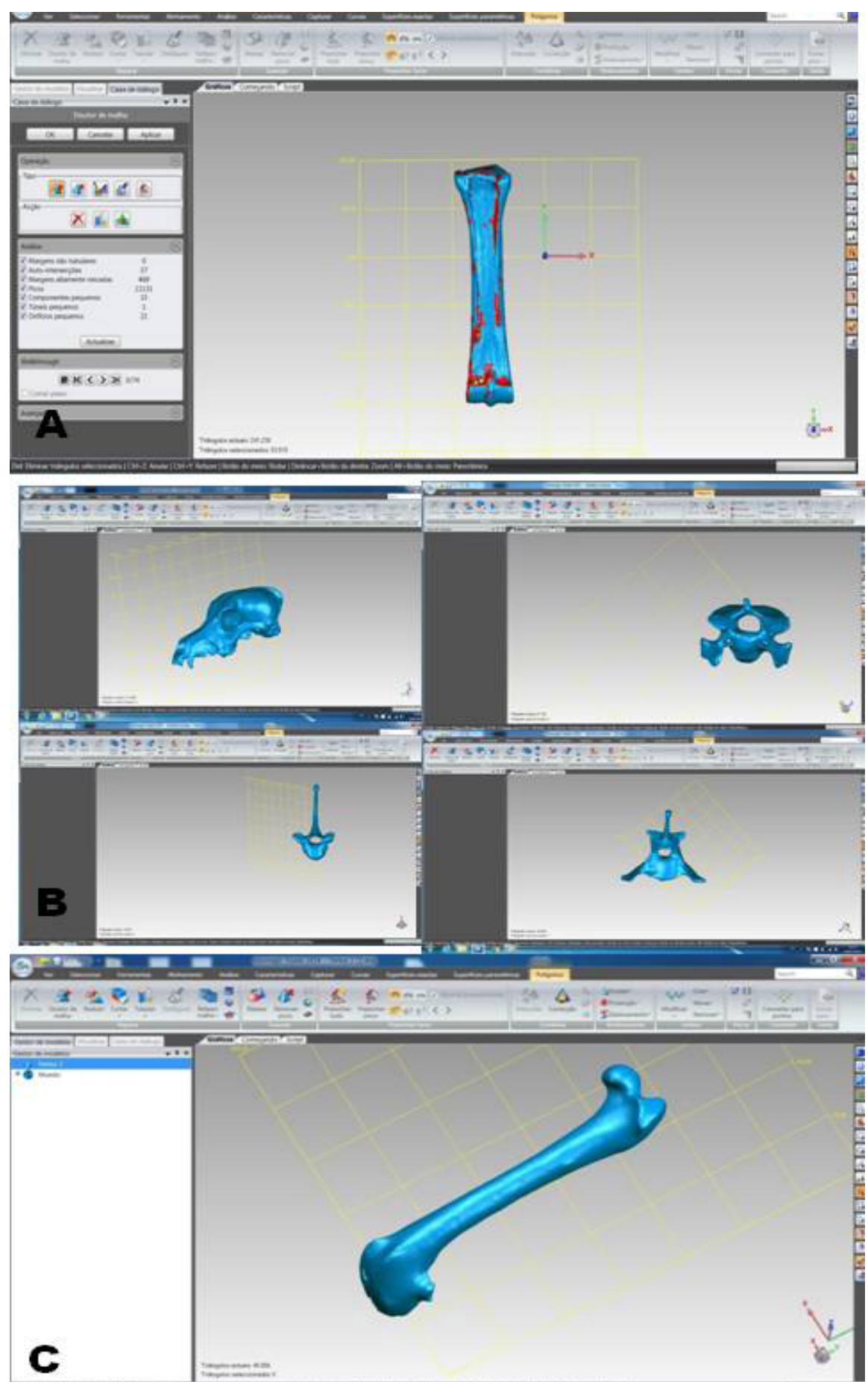

Figura 1 - Procedimentos de edição das imagens digitalizadas por meio do software Geomagic. (A) Ossos do metatarso equino. (B) Ossos do crânio e vértebras cervical, torácica e lombar de cão. (C) Fêmur equino. 

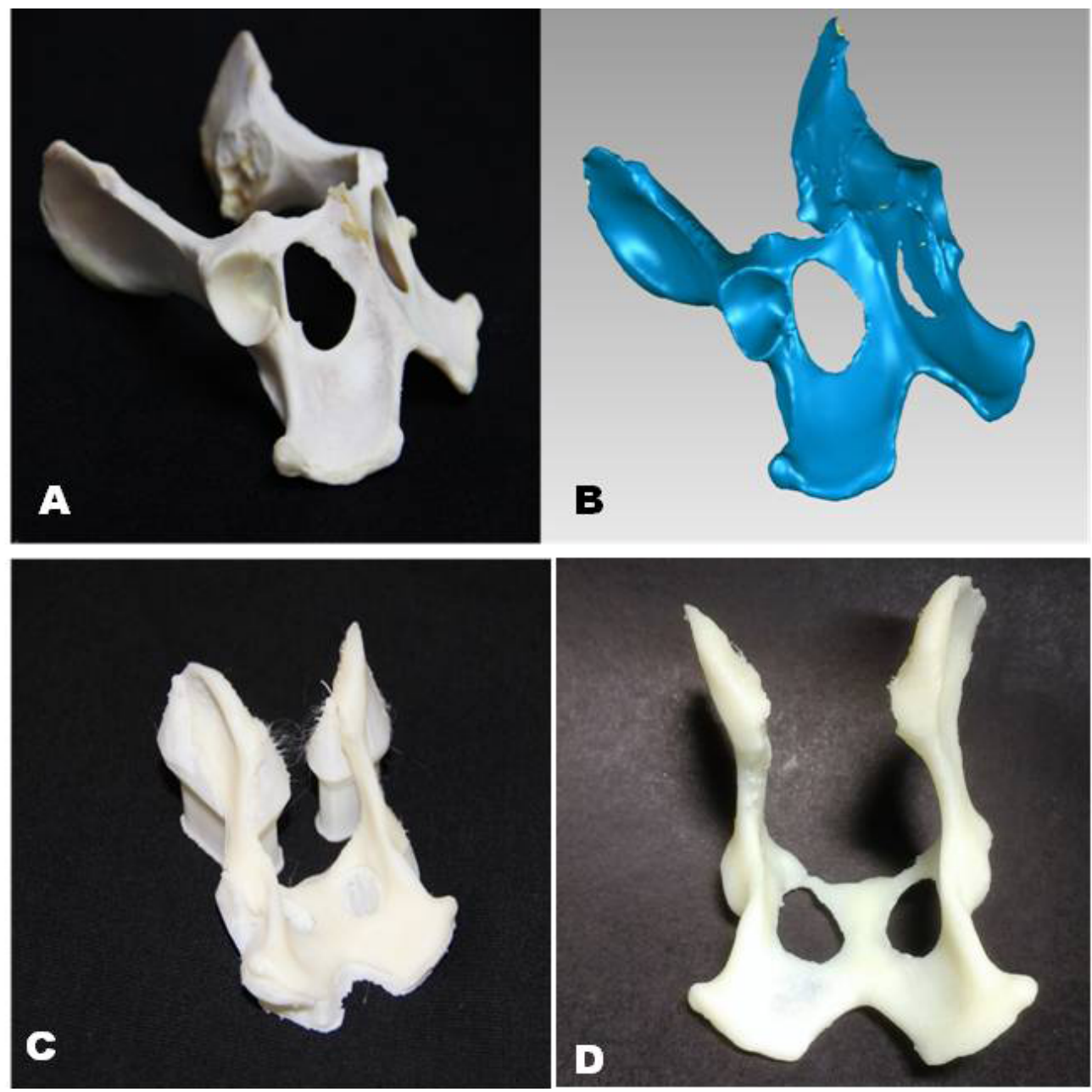

Figura 2 - Etapas da produção de um biomodelo do osso coxal de um cão. Imagens real (A) e digitalizada (B) do osso coxal. Biomodelo do osso coxal de um cão (C) produzido com o uso de impressora 3D, nesta imagem pode ser observado osso ainda com a resina de suporte. Biomodelo do osso coxal de um cão (D) finalizado.

\section{Resultados}

Das espécies do presente estudo foram digitalizados os ossos do esqueleto apendicular, com exceção das falanges e da patela do cão. Na etapa da impressão, os biomodelos do cão foram produzidos em tamanho real. Para a espécie equina, a escápula, úmero, rádio, ulna, fêmur, tíbia e fíbula foram impressos em uma escala com $70 \%$ do tamanho real, e os ossos do coxal em uma escala com 20\% do tamanho real (Figura 2). Os ossos metacarpos, metatarsos, ossos do carpo, ossos do tarso, sesamoides e falanges foram impressos em tamanho real.

O material termoplástico usado na impressão possuía uma coloração marfim bem próxima da cor dos ossos. Os biomodelos impressos apresentaram as mesmas características anatômicas dos ossos dos animais, as particularidades ósseas foram preservadas, mostrando a fidedignidade das réplicas produzidas (Figura 3).

Com a digitalização foi produzido um acervo digital com as imagens, que podem ser reproduzidas em telas gigantes interativas tocáveis (tipo tablets) de sessenta polegadas, dispostas verticalmente na sala de aula prática do Laboratório de Anatomia Veterinária, onde os alunos podem interagir com o material, girar a imagem em vários ângulos e identificar as particularidades e estruturas anatômicas (Figura 4 e figura 5).

\section{Discussão}

O trabalho traz resultados positivos e promissores na produção de biomodelos ósseos das espécies canina e equina utilizados para fins didá- 


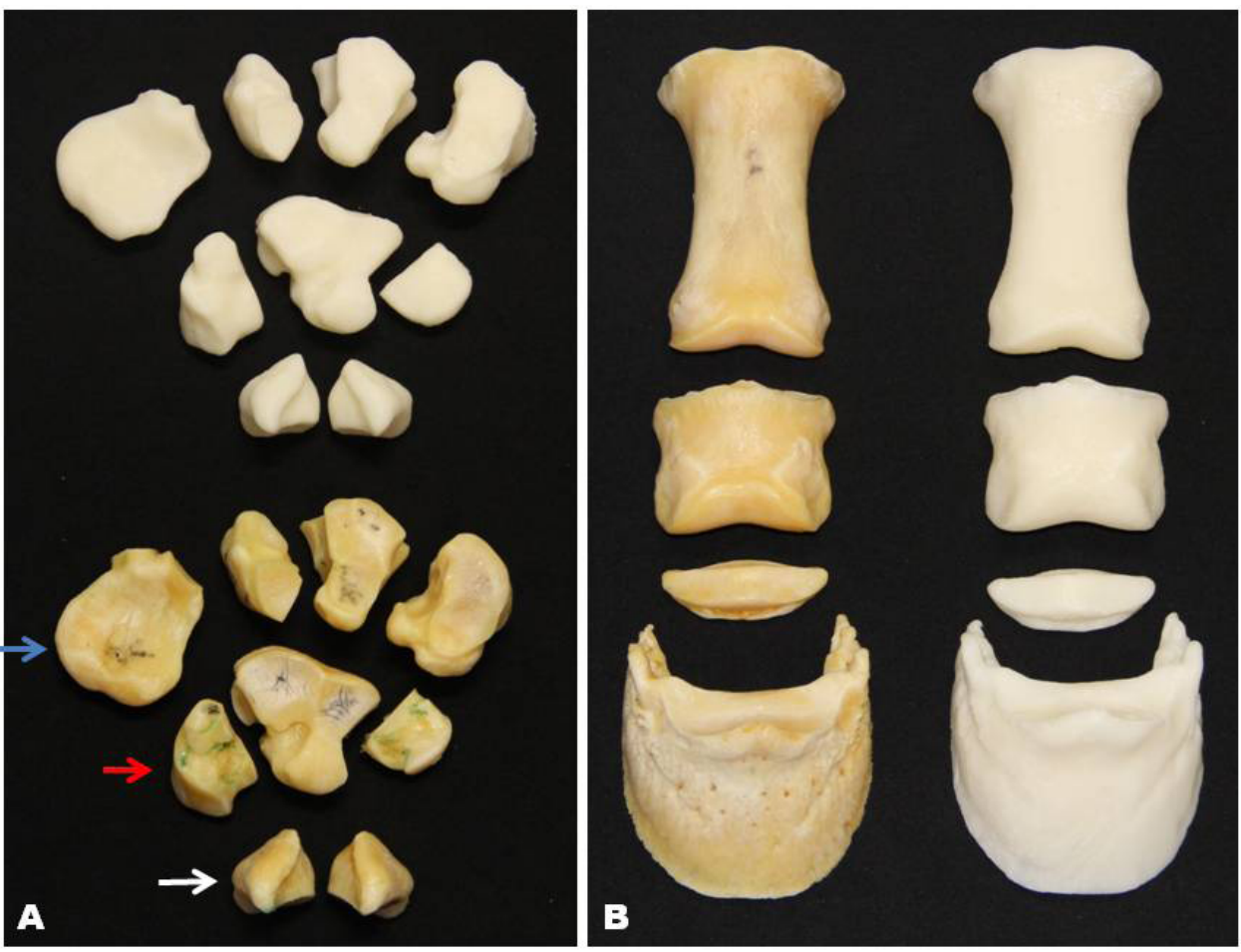

Figura 3 - (A) Parte superior: biomodelos replicados. Na parte inferior, ossos do carpo reais (macerados) de um equino - ossos do carpo do cavalo: ossos carpos acessório, ulnar, intermédio radial (fileira proximal, seta azul); II, III e IV: ossos do carpo (fileira distal, seta vermelha); e ossos sesamoides proximais (seta branca). (B) Imagem à esquerda: falanges proximal, média e distal; imagem à direita: réplicas bioimpressas das falanges proximal, média e distal.

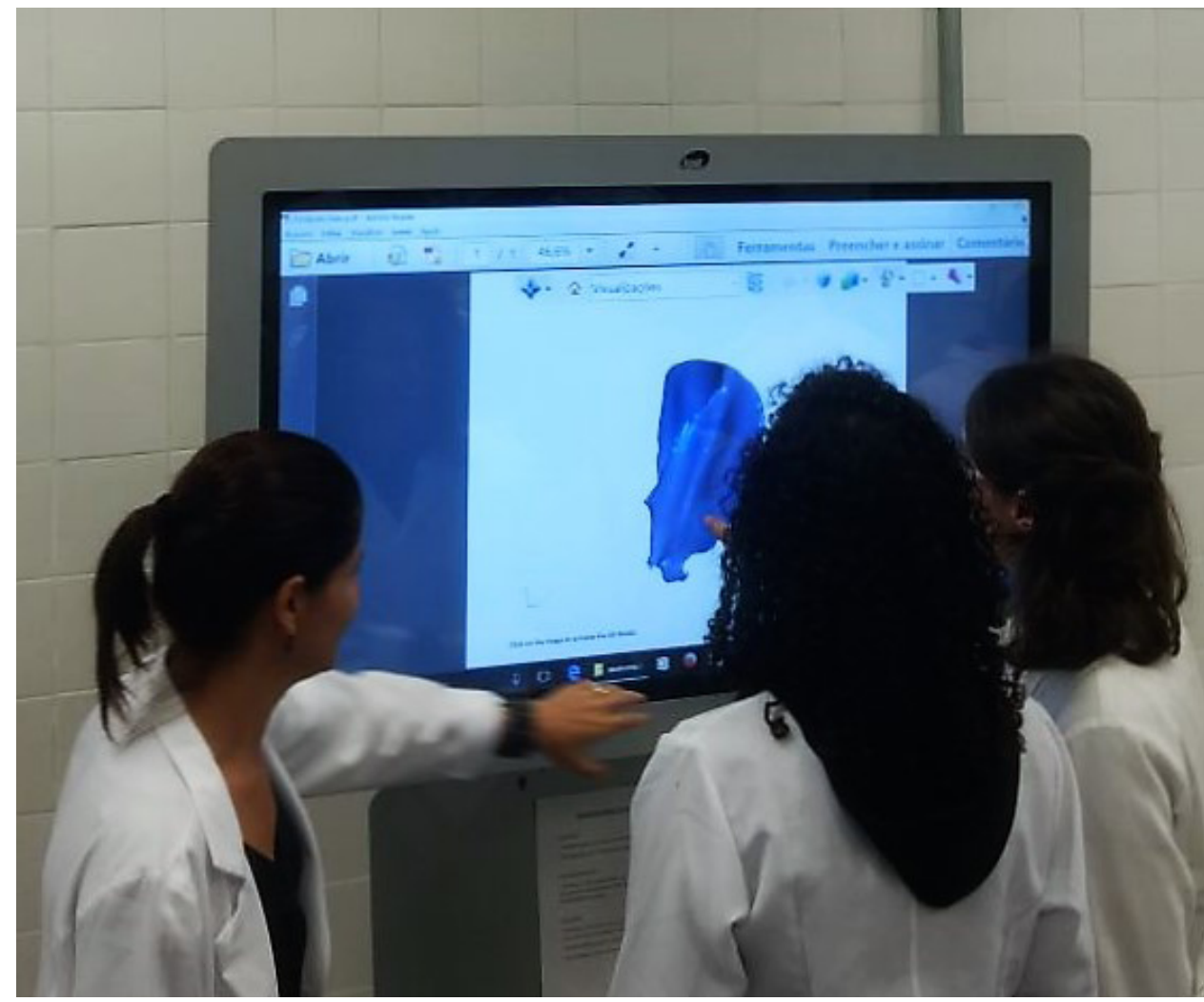

Figura 4 - Interação dos alunos com os arquivos digitais dispostos em telas interativas tipo tablets durante as aulas práticas de anatomia veterinária, FMVZ/USP. 

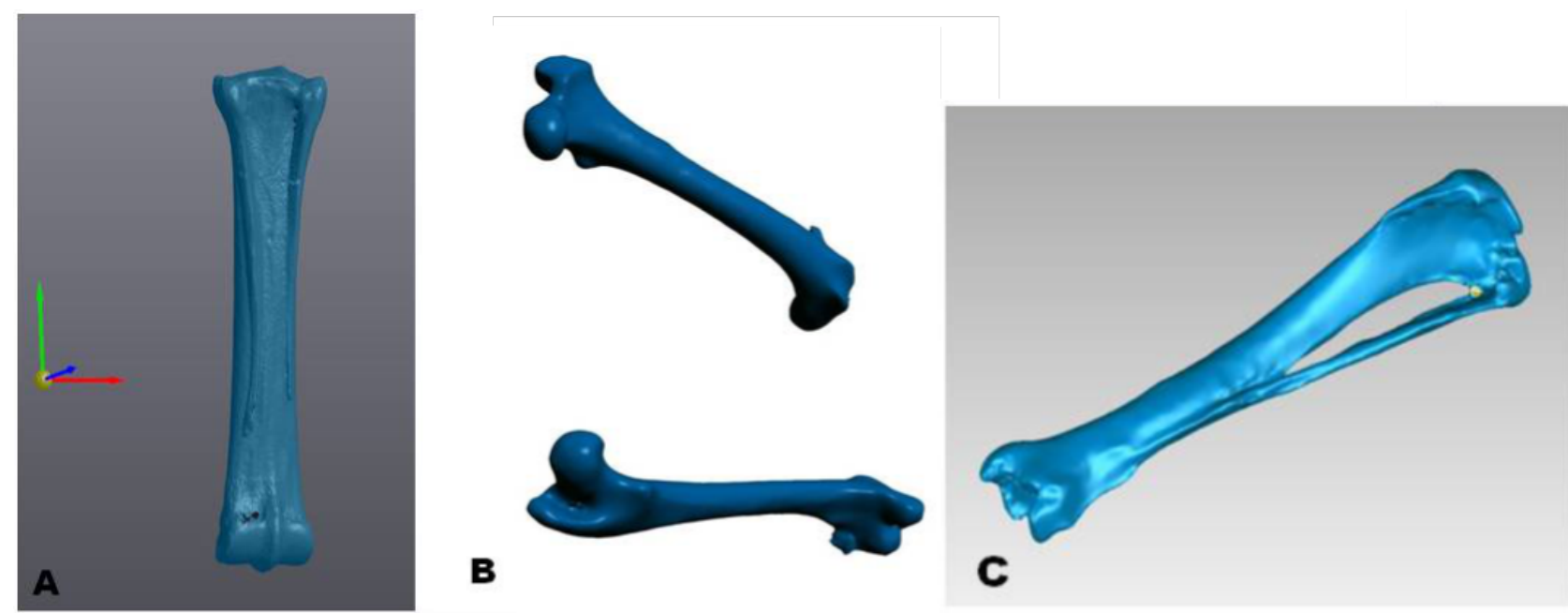

Figura 5 - Arquivos digitais interativos produzidos que podem ser instalados nos tablets. (A) Ossos metacárpicos II, III e IV de um equino; (B) Fêmur de um cão nas vistas cranial e caudal; e (C) Tíbia e fíbula de um cão.

ticos. Como demonstrado, a morfologia dos ossos do crânio e membros torácicos e pélvicos de cão e de equino foram digitalizados e impressos, e as principais estruturas anatômicas foram preservadas para estudos comparativos das espécies de interesse veterinário (Figuras 1, 2, 3 e 5). Materiais como os produzidos neste trabalho fazem com que a impressão 3D seja uma tecnologia emergente também para a produção de modelos anatômicos voltados para o ensino na área da Anatomia Animal, seja nos cursos de Medicina Veterinária, Zootecnia, Biologia ou outras áreas correlacionadas às Ciências Agrárias.

As impressoras 3D, antes presentes somente nas grandes empresas devido ao custo elevado, agora estão mais populares, pois foram desenvolvidas tecnologias que as tornaram bem mais acessíveis, podendo ser adquiridas por instituições educacionais como universidades (TAKAGAKI, 2012, pp. 28-40).

Os biomodelos, quando aplicados em salas de aula, não apresentam desvantagens em relação ao modelo animal real. Além da geração de modelos fidedignos, a quantidade de peças impressas pode ser maior que a quantidade de cadáveres disponíveis. As aulas de anatomia podem ficar mais completas em termos comparativos, uma vez que a variedade de espécies animais disponível poderá ser bem maior, com a impressão de estruturas anatômicas de animais silvestres, por exemplo (THOMAS et al., 2016, pp. 473-481).
Sendo os biomodelos produzidos a partir de um material termoplástico, sua utilização como material didático não fica restrita aos laboratórios de anatomia, podendo ser usados também em outros locais, como bibliotecas e salas de aula (WEN, 2016, pp. 7-16).

O ensino da Anatomia, humana ou animal, sempre foi alvo de grandes discussões devido ao uso de cadáveres e, consequentemente, ao uso de produtos como formol para a conservação das peças. A utilização desses biomodelos, assim como de órgãos viscerais, amenizará esses inconvenientes (McMENEMIN et al., 2014, pp. 298-310).

Os biomodelos produzidos através da impressão 3D também se mostraram economicamente viáveis em relação à obtenção, ao preparo e à conservação de peças anatômicas de cadáveres (CHEN et al., 2017, pp. 1-11).

O conhecimento em anatomia do futuro profissional se beneficia com o emprego dos biomodelos por impressão 3D e dos arquivos digitais interativos, pois estes promovem o entusiasmo do aluno em aprender com novas tecnologias; além disso, o uso de peças de cadáveres geralmente desencadeia efeito psicológico negativo no aluno, e as peças anatômicas, por serem difíceis de obter, muitas vezes se apresentam danificadas, prejudicando o estudo detalhado das estruturas anatômicas (CHEN et al., 2017, pp. 1-11). 
Em alguns países onde se localizam as universidades consideradas as melhores do mundo, estão sendo desenvolvidos projetos que incluem a reorganização da matriz curricular, capacitação do corpo docente, reformulação dos laboratórios de anatomia, com desenvolvimento de tecnologias interativas educacionais destinadas a facilitar a aprendizagem do aluno (WEN, 2016, pp. 7-16).

Os biomodelos e os arquivos digitais produzidos poderão ser aplicados como uma forma alternativa e complementar para o estudo anatômico do esqueleto canino e equino. Em virtude da existência de poucos trabalhos utilizando a tecnologia 3D na área de ensino da Anatomia Animal, esse trabalho assume papel importante na introdução de biomodelos como meio didático alternativo no ensino anatômico, no entanto os estudos devem ser continuados para validar o método na relação ensino-aprendizagem dos acadêmicos nos cursos de medicina veterinária.

\section{Agradecimentos}

Ao Programa Unificado de Bolsas de Estudos, Edital 2015/2016 - Pró-Reitoria de Graduação, Pró-Reitoria de Pesquisa, Pró-Reitoria de Cultura e Extensão da Universidade de São Paulo, pelas bolsas aos alunos.

Ao Programa Renovalab - Pró-Reitoria de Graduação.

\section{Referências Bibliográficas}

BOYD, Sharon; CLARKSON, Eoghan \& MATHER, Brian. "Learning in the Third Dimension". Veterinary Record, vol. 176, pp. 1-2, abr. 2015.

CHEN, Shi et al. "The Role of Three-Dimensional Printed Models of Skull in Anatomy Education: a Randomized Controlled Trail". Scientific Reports, vol. 7, n. 1, pp. 1-11, 3 abr. 2017. Springer Nature. http://dx.doi. org/10.1038/s41598-017-00647-1.

GRANDE NETO, Newton Salvador. Utilização de Material Alternativo para a Obtenção e Caracterização de Biomodelos, por meio da Técnica de Impressão 3DPRINTER. 2016. 56 f. Dissertação (Mestrado), Faculdade de Engenharia, Universidade Estadual Paulista, Ilha Solteira, 2016. Disponível em: <http://repositorio. unesp.br/bitstream/handle/11449/137869/grandeneto_ns_me_ilha.pdf?sequence $=3>$. Acessado em $1^{\circ}$ maio 2016.

HESPEL, Adrien-Maxence; WILHITE, Ray \& HUDSON, Judith. "Invited Review-Applications for 3D Printers in Veterinary Medicine". Veterinary Radiology \& Ultrasound, v. 55, n. 4, pp. 347-358, 2014.

McMENEMIN, P. G.; QUAYLE, M. R.; McHENRY, C. R. \& ADAMS, J. W. "The Production of Anatomical Teaching Resources Using Three-Dimensional (3D) Printing Technology". Anatomical Science Education, vol. 7, pp. 479-486, 2014.

SEARS, N. A.; SESHADRI, D. R.; DHAVALIKAR, P. S. \& COSGRIFF-HERNANDEZ, E. "A Review of Three-Dimensional Printing in Tissue Engineering". Tissue Engineering. Part B, Reviews, vol. 22, pp. 298-310, 2016.

SILVA, Francisco da \& ROSADO, Victor Orlando Gamarra. "Biomodelagem Virtual para Diagnóstico e Planejamento Cirúrgico Usando Softwares Livres". Informática na Educação: Teoria e Prática, Porto Alegre, vol. 17, n. 1, pp. 125-143, jan.jun.2014.

TAKAGAKI, Luiz Koiti. "Tecnologia de Impressão 3D". Revista de Inovação Tecnológica, São Paulo, vol. 2, n. 2, pp. 28-40, jul. 2012. Disponível em: <http:// rit.faculdadeflamingo.com.br/ojs/index.php/rit/article/ view/54>. Acessado em 10 maio 2017.

THOMAS, D. B.; HISCOX, J. D.; DIXON, B. J. \& POTGEITER, J. "3D Scanning and Printing Skeletal Tissues for Anatomy Education". Fournal of Anatomy, vol. 229, pp. 473-481, 2016.

WEN, Chao Lung. "Homem Virtual (Ser Humano Virtual 3D): A Integração da Computação Gráfica, Impressão 3D e Realidade Virtual para Aprendizado de Anatomia, Fisiologia e Fisiopatologia". Grad+: Revista de Graduação da USP, vol. 1, n. 1, pp. 7-16, 5 jul. 2016. 